\title{
O ENSINO DE ESPANHOL NA FRONTEIRA DE JAGUARÃO/BR E RIO BRANCO/UY: ANÁLISE DOS LIMITES E PERSPECTIVAS EDUCACIONAIS APÓS REVOGAÇÃO DA LEI N ${ }^{\circ} 11.161 / 2005^{i}$
}

\author{
THE TEACHING OF SPANISH IN THE BORDER OF JAGUARÃO/BR AND RIO \\ BRANCO/UY: ANALYSIS OF BOUNDARIES AND PERSPECTIVES AFTER THE \\ REPEAL LAW No 11.161/2005
}

\begin{abstract}
Caroline Gonçalves Feijó-Quadrado Mestranda em Educação pelo Programa de Pós-Graduação em Educação da Universidade Federal do Pampa, campus Jaguarão/RS. Assistente em Administração na Universidade Federal do Pampa, campus Jaguarão/RS. Jaguarão, Rio Grande do Sul, Brasil. carolinefeiijo@gmail.com
\end{abstract}

Alessandra Troian Doutora em Desenvolvimento Rural. Docente na Universidade Federal do Pampa, campus Santana do Livramento/RS. Santana do Livramento, Rio Grande do Sul, Brasil. alessandratroian@unipampa.edu.br

Resumo: A partir da revogação da Lei no 11.161/2005 e da opcionalidade para o ensino de língua espanhola nas escolas brasileiras, a presente pesquisa visa investigar a oferta do idioma no município de Jaguarão/BR, fronteiriço com Rio Brando/UY. Especificamente, busca-se: a) verificar as medidas tomadas pelo poder público local para a garantia de ensino de espanhol; b) identificar os limites e as perspectivas encontrados pela gestão educacional do Executivo em relação à oferta da disciplina. Metodologicamente, o estudo caracteriza-se como qualitativo, realizado a partir de pesquisa documental e de um grupo focal com o Secretário de Educação e a Coordenadora Pedagógica municipal. Como resultado, identificou-se que o Poder Legislativo aprovou alterações na Lei Orgânica e que, em algumas escolas, o ensino do idioma foi condensado.

Palavras-chave: Ensino de espanhol. Fronteira. Gestão Educacional.

\begin{abstract}
Since the repeal of Law 11,161/2005 and the optionality for teaching Spanish in Brazilian schools, this research aims to investigate the language offer in the municipality of Jaguarão/BR, bordering Rio Branco/UY. Specifically, it seeks to: a) verify the measures taken by the local public authority to guarantee spanish teaching; b) identify the limits and the perspectives found by the educational management of the Executive in relation to the offer of the discipline. Methodologically, the study is characterized as qualitative, based on documentary research and focus group with the education secretary and the municipal pedagogical coordinator. As a result, it was identified that the Legislative Branch approved changes in the Organic Law and that, in some schools, language teaching was condensed.
\end{abstract}

Key-words: Spanish Teaching. Country Border. Educational management. 


\section{Introdução}

endo passado mais de uma década da aprovação da Lei Federal no 11.161, de agosto de 2005, que previa a oferta obrigatória do ensino de espanhol nas escolas de todo o Brasil, L constituindo-se como uma ação político linguística de ampliação do ensino de línguas e culturas estrangeiras nas escolas, atualmente, o cenário é outro.

Em 2016, o Governo Federalii propôs a Reforma do Ensino Médio. Inicialmente, através da Medida Provisória (MP) n $n^{\circ} 746 / 2016$ que, depois de analisada pelo Congresso Nacional, foi transformada na Lei Federal n 13.415/2017. Entre as mudanças mais significativas resultantes da nova legislação está a revogação da Lei n ${ }^{\circ} 11.161 / 2005$, que deixa de considerar o ensino de língua espanhola como obrigatório nas escolas brasileiras. Com a Reforma do Ensino Médio, foi acrescentado à Lei de Diretrizes e Bases da Educação Nacional (LDB), de 1996, o art. 35-A, cujo parágrafo quarto tornou obrigatório apenas o ensino da língua inglesa e optativo o ensino de outras línguas estrangeiras, dando preferência ao espanhol nos casos em que houver disponibilidade pelos sistemas de ensino.

No entanto, o ensino de línguas estrangeiras, como a espanhola, por exemplo, torna-se fundamental em algumas regiões do país. Segundo Boéssio (2010), o ensino do espanhol em zonas de fronteira proporciona a integração linguística, política, econômica, histórica e cultural entre os países vizinhos; além de propiciar aos estudantes conhecer o contexto em que estão inseridos e a oportunidade de atuar e interagir em seu cotidiano, conhecendo e valorizando as línguas e culturas com as quais têm contato.

Neste sentido, a partir do cenário nacional apresentado, a presente pesquisa visa investigar a oferta do ensino de espanhol no município de Jaguarão/BR, fronteiriço com Rio Branco/UY. Como objetivos específicos têm-se: a) verificar as medidas tomadas pelo poder público local para a garantia de ensino de espanhol; b) identificar os limites e as perspectivas encontrados pela gestão educacional do Executivo em relação à oferta da disciplina.

A pesquisa justifica-se na medida em que a revogação da Lei nº 11.161/2005 implica na oferta do ensino de espanhol nas escolas do Brasil e, especialmente, em vinte e sete municípios gaúchos que fazem fronteira com o Uruguay e/ou a Argentina. Como a alteração da LDB é recente, considera-se relevante desenvolver pesquisas que apresentem a situação do ensino da língua espanhola em escolas de cidade fronteiriças. Salienta-se que Jaguarão localiza-se cerca de $387 \mathrm{~km}$ da capital gaúcha, Porto Alegre, e 396 km de Montevidéu, capital uruguaia. 


\section{QUADRADO, Caroline Gonçalves Feijó; TROIAN, Alessandra}

\section{O ensino de espanhol em escolas públicas de cidades de fronteira}

Nesta seção serão apresentadas as concepções nacionais em relação ao ensino de línguas estrangeiras presentes na LDB (1996) e na Base Nacional Comum Curricular (BNCC, 2016). Após, serão apresentadas as concepções acerca do ensino de espanhol presentes nos Parâmetros Curriculares Nacionais (PCN, 2000) e nas Orientações Curriculares para o Ensino Médio (OCEM, 2006). Também serão discutidas questões acerca do ensino de espanhol na fronteira. Por fim, será apresentado o inconstante processo da oferta do ensino de espanhol no Brasil.

\subsection{O ensino da língua espanbola nas escolas}

Com as recentes modificações realizadas na LDB é pertinente destacar o cenário em relação ao ensino de espanhol nos documentos legais que balizam a educação básica brasileira. Com a publicação da Lei Federal n 13.415/2017, foi incluído, na LDB, o art. 35-A:

\footnotetext{
$\int 40$ Os currículos do ensino médio incluirão, obrigatoriamente, o estudo da língua inglesa e poderão ofertar outras línguas estrangeiras, em caráter optativo, preferencialmente o espanhol, de acordo com a disponibilidade de oferta, locais e horários definidos pelos sistemas de ensino (BRASIL, 1996).
}

Além disso, como já mencionado na introdução, a Lei 13.415/2017, revogou a Lei 11.161/2005, que dispunha sobre o ensino de espanhol. Em consequência, a BNCC (2017) também desconsidera o espanhol como um dos componentes da área de linguagens, indicando apenas o inglês como componente obrigatório.

Neste sentido, destaca-se alguns dos documentos nacionais que apresentam relevantes concepções sobre o ensino de línguas estrangeiras, a saber: os Parâmetros Curriculares Nacionais (PCN, 2000); e as Orientações Curriculares para o Ensino Médio (OCEM, 2006).

De acordo com os PCN, o ensino de uma língua estrangeira deve levar em consideração seus valores sociais, culturais, políticos e ideológicos; e, além disso, em vez de focar unicamente nas habilidades linguísticas, deve levar em consideração as competências a serem dominadas.

\footnotetext{
Para poder afirmar que um determinado indivíduo possui uma boa competência comunicativa em uma dada língua, torna-se necessário que ele possua um bom domínio de cada um dos seus componentes. Assim, além da competência gramatical, o estudante precisa possuir um bom domínio da competência sociolingǘstica, da competência discursiva e da competência estratégica (PCN, 2000, p. 29).
}

Além disso, para se comunicar em uma língua estrangeira é preciso mais do que a 
capacidade de compor frases corretas, mas, sim, compreender e dominar o contexto linguístico e cultural da língua alvo (PCN, 2000, p. 29).

As OCEM (2006) trazem um capítulo específico sobre o ensino de espanhol. De acordo com o documento, o ensino de uma língua estrangeira tem a intenção de desenvolver a sensibilidade linguística do aluno, de modo que ele estabeleça relações entre as características da língua alvo e de sua língua materna. Destaca que, no processo de ensino e de aprendizagem, é necessário desenvolver a confiança do aprendiz através de experiências bem-sucedidas de uso da língua estrangeira. Assim, o aluno pode se sentir mais confiante para enfrentar os desafios cotidianos e sociais, adaptando-se a usos diversos da linguagem em diferentes situações (OCEM, 2006).

Em relação ao ensino de espanhol, especificamente, as OCEM destacam, ao longo da proposta,

Conceitos de língua, de cultura e das formas de trabalhá-las; do papel educativo que pode ou deve ter o ensino [...] do Espanhol [...] na formação do estudante, naquilo que esse lhe proporciona em termos de inclusão social e étnica, na constituição de sua cidadania, local e global; dos desafios que nos impõe, nesse sentido, uma sociedade globalizada, informatizada, em que as próprias fronteiras das tradicionais formas de manifestação da linguagem, antes tratadas no ensino de línguas como as quatro habilidades - compreensão escrita, compreensão oral, expressão escrita, expressão oral -, se interpenetram e diluem (OCEM, 2006; p. 129).

O documento, também menciona que as concepções expostas devem ser revistas e, se necessário, readequadas de acordo com cada contexto e com cada instituição, para atender os desafios das realidades que estão em permanente transformação (OCEM, 2006). Soma-se a estes conceitos a ideia trazida pela BNCC, que

defiende una concepción de lenguajes como 'construcción humana, histórica, social y cultural, de naturaleza dinámica, reconociéndolos y valorándolos como formas de significación de la realidad y expresión de subjetividades e identidades sociales y culturales' (FERNÁNDEZ, 2018, p. 14).

Embora a questão de como e o que ensinar seja algo mais familiar ao contexto docente, os gestores educacionais não podem deixar de ter conhecimento sobre as concepções que regem o ensino curricular, pois, cabe a ele, além de conduzir os processos de formação docente, participar da proposição de políticas públicas.

A partir das ideias apresentadas em relação ao ensino de espanhol como língua estrangeira, destacadas dos documentos nacionais, surge o questionamento: como é, ou deveria ser, o ensino do espanhol em zonas de fronteira com países que têm esta como língua materna? O que dizem os estudos que tratam sobre estes contextos especificamente? 


\section{QUADRADO, Caroline Gonçalves Feijó; TROIAN, Alessandra}

\subsection{O ensino de espanhol em zonas de fronteira}

Quando se fala em cidades fronteiriças, parece natural que o ensino da língua do país vizinho seja algo intrínseco às escolas. Ao ensinar a língua do país vizinho, além de estar formando o aluno para aproximação e integração linguística, política, econômica, histórica e cultural e propiciando aos estudantes conhecer o contexto em que estão inseridos, interagindo e valorizando as línguas e culturas com as quais têm contato, também se está contribuindo com a qualificação dos discentes, que poderão encontrar melhores oportunidades no mercado de trabalho (BOÉSSIO, 2010). Soma-se a estas questões, a oportunidade da escola em contribuir e mostrar para o aluno o processo de formação do sujeito fronteiriço, que tem sua identidade construída a partir do contato linguístico e cultural entre os dois países (FARIS-MARQUES, 2016).

No entanto, estudos demonstram que a realidade em relação ao ensino da língua do país vizinho nem sempre é como se espera. Sturza (2018), após apresentar um panorama histórico sobre as relações entre o Brasil e os demais países da América do Sul, menciona as dificuldades resultantes das políticas nacionais brasileiras que, ao longo do tempo, vêm construindo uma cultura linguística monolíngue.

Segundo Sturza (2018, p. 43), a cultura monolíngue mostra que "en las zonas de frontera, aunque la gente hable un portugués impregnado de español, se niegan a reconocerlo" e isto "nos permite reflexionar sobre la resistencia que encontramos en incluir el español en nuestro sistema escolar" e sobre a complexidade em "sensibilizar a los estudiantes sobre la lengua del otro" (STURZA, 2018, p. 43).

Esta realidade evidencia a importância da reflexão sobre o processo de ensino de espanhol em zonas de fronteira, mas, além disso, demonstra a necessidade de criação de uma política nacional (ou local) de ensino de Línguas Estrangeiras (LE), pois:

[...] desde sua implementação, o ensino das LE no contexto escolar brasileiro tem sido regulado pela autoridade do Estado, ou seja, por governantes com poderes para tal, que determinam, por razões diversas, quais línguas devem ser ensinadas no país, para quem, por quanto tempo. Trata-se de escolhas importantes que, se exercidas com coerência e planejamento, com objetivos claros, diretrizes e metas exequíveis, compõem o que se denomina uma Política de Ensino de Línguas (PoELin) (BUSSO, 2016, p. 15).

A falta de uma política linguística sólida que trate sobre o ensino de espanhol, prejudicado com a Reforma do Ensino Médio, “imprime un nuevo desafío de lucha y resistencia para mantener el derecho de enseñar y aprender español en las escuelas fronterizas brasileñas", onde o motivo de aprender uma língua "cuyos hablantes transitan por la ciudad no implica solamente el apropiarse de 'una lengua extranjera', [...] se trata de construir oportunidades hacia una visión cultural, social, política e histórica más amplia y plural' (ZWARG; ARF; BARREDA, 2018, p. 96). 
(DMMRDC, s.a) estabelece concepções que podem ser norteadoras em relação ao ensino de espanhol nas escolas de fronteira. De acordo com o documento,

\begin{abstract}
una educación para las escuelas de frontera [... implica el conocimiento y la valorización de las culturas involucradas a través de prácticas interculturales. Como efectos de la integración, negociación y del diálogo entre los grupos, se pone en escena, entonces, relaciones entre las culturas, el reconocimiento de las características propias, el respeto mutuo y la valoración de lo diferente como tal (y no como "mejor" o "peor") (DMMRDC, s.a., p. 17-18).
\end{abstract}

Neste panorama, entende-se interculturalidade como "un conjunto de prácticas sociales relacionadas con el 'estar con el otro" e como "conocimientos sobre el otro, sobre el otro país, sus formas históricas de constitución y de organización, conocimientos que necesitan estar presentes [...] en las escuelas" (DMMRDC, s.a, p. 18). A visão intercultural, ao mesmo tempo que possibilita uma visão do outro, contribui com o processo de construção da identidade fronteiriça, que se constitui pelas mesclas do cruzamento das duas línguas e culturas.

A partir do que foi exposto, tem-se uma breve noção acerca do ensino de espanhol em cidades fronteiriças, apontando para a necessidade de criação de estratégias "de la gestión escolar de la municipalidad que, en una toma de decisión, nos muestra cómo se puede valorar el español como una lengua no extranjera sino cercana, de la vecindad' (STURZA, 2018, p. 46). Para tanto, o item a seguir apresentará informações sobre o inconstante processo da oferta do ensino de espanhol no Brasil.

\title{
2.3 O inconstante processo de oferta do espanbol nas escolas brasileiras
}

O ensino de espanhol nas escolas regulares do Brasil vem sendo demarcado, ao longo da história, por diversas orientações oficiais e políticas públicas que demonstram certa descontinuidade em relação à sua oferta, além de refletir um inconstante processo, marcado por altos e baixos (FERNÁNDEZ, 2018).

De acordo com Fernández (2018, p. 9), as diferentes orientações oficiais “ban llevado a que algunos idiomas hayan ocupado un lugar más o menos privilegiado, mientras otros no han sido considerados de gran importancia”. A afirmação pode ser comprovada a partir da Lei Federal n 13.415/2017, quando o Governo brasileiro passou a considerar apenas o inglês como língua estrangeira obrigatória nos currículos escolares.

A implantação da Lei 11.161, em 2005, "se tornou um marco da política externa brasileira para a América do Sul e para outros países da Europa" (ALVAREZ, 2018, p. 22), pois constituía-se como uma forte ação político-linguística. Sua revogação, em 2017, conforme Fernández (2018, p. 10). "va a contramano de lo que exige el mundo plural actual y de lo que se espera lograr durante la etapa de formación básica de los estudiantes". Além disso, demonstra que o Brasil está retrocedendo não só por retirar um dos idiomas que compunha o currículo, mas por limitar o contato dos alunos com outros idiomas durante 


\section{QUADRADO, Caroline Gonçalves Feijó; TROIAN, Alessandra}

e-ISSN: 2525-3514

o processo de escolarização.

A história até aqui desenhada nos permite identificar que as ações federais estabelecem "una politica lingüística restrictiva y monolingüe” (FERNÁNDEZ, 2018, p. 15). No entanto, para Boessio (2010) é evidente a importância de políticas públicas locais adequadas às realidades fronteiriças, já que, nestes lugares, as relações mesclam, naturalmente, culturas e línguas.

Neste sentido, "como un gesto de resistencia, como muestra de la importancia que le dan a una educación de calidad y como prueba del compromiso con la formación integral de los estudiantes" (FERNÁNDEZ, 2018, p. 15) algumas cidades brasileiras, por iniciativa dos professores de espanhol e/ou autoridades competentes,

[...] se anticipan $y$, sin infringir la mencionada y restrictiva ley nacional, crean mecanismos locales - de cada estado o municipio - para incorporar y asegurar el mantenimiento de la lengua española en la enseñanza pública (FERNÁNDEZ, 2018, p. 15-16).

Partindo destas ações de resistência e da possibilidade de manutenção da oferta de espanhol como obrigatória, torna-se necessário verificar como está o ensino do idioma nas cidades fronteiriças após a reforma do ensino médio. Assim, a seguir será apresentada a metodologia utilizada para a coleta e análise dos dados da presente pesquisa.

\section{Metodologia}

O estudo caracteriza-se como qualitativo. Segundo Silveira e Córdoba (2009, p. 32), o estudo qualitativo é aquele que se preocupa com aspectos da realidade que não podem ser quantificados. Também são definidos como aqueles que estão centrados na compreensão e explicação da dinâmica das relações sociais. Como técnicas de coleta de dados foram utilizadas a pesquisa documental e o grupo focal. O grupo focal foi realizado mediante roteiro elaborado previamente, baseado na literatura sobre o tema.

De acordo com Marconi e Lakatos (2010, p. 157), a pesquisa documental caracteriza-se pela coleta de dados "restrita a documentos, escritos ou não, constituindo o que se denomina de fontes primárias". Já o grupo focal é uma técnica que permite a interação entre os participantes, também propicia um espaço aberto de discussões sobre os tópicos da pesquisa (GUI, 2003), favorecendo uma comunicação espontânea e um ambiente natural de comunicação.

A pesquisa documental foi realizada no site da Câmara de Vereadores do município de Jaguarão. Foram analisados o Projeto de Lei Municipal nº 005/2018, que dispõe sobre a inclusão da disciplina de Língua Espanhola no currículo do ensino fundamental, anos finais, nas escolas municipais e dá outras providências; e o Projeto de Emenda à Lei Orgânica Municipal 001/2018, que busca incluir na Lei Orgânica Municipal o ensino de espanhol no currículo do ensino fundamental/anos finais e na modalidade de Educação de Jovens e Adultos (EJA). 
A coleta de dados primários deu-se por meio de um grupo focal. Destacase que o grupo focal geralmente é utilizado em grupos de oito ou mais pessoas, no entanto, nesta pesquisa ele ocorreu com dois participantes, Secretário de Educação e Coordenadora Pedagógica. A atividade foi realizada em setembro de 2018, na Secretaria de Educação e Desporto de Jaguarão. A conversa foi gravada e durou cerca de 35 minutos, após, as falas foram transcritas e analisada a partir de uma aproximação à análise de conteúdo proposta por Bardin (2011).

\section{$4 \mathrm{O}$ ensino de espanhol nas escolas municipais de jaguarão}

Neste item serão apresentados os resultados da pesquisa. A primeira seção aborda a atuação do Poder Legislativo e Executivo de Jaguarão em prol da garantia do ensino de espanhol nas escolas do município. Em seguida serão evidenciados os limites e as perspectivas encontrados pelos gestores educacionais em relação ao ensino do idioma no município.

\subsection{As políticas educacionais locais para manutenção do espanbol nas escolas}

Através de pesquisa documental identificou-se duas ações propostas pela Câmara de Vereadores relacionadas à manutenção da oferta do ensino de espanhol: o Projeto de Lei (PL) 005/2018, que foi proposto em maio de 2018 e aprovado em outubro do mesmo ano está em estágio de Instrução da Comissão de Constituição e Justiça (CCJ); e a Proposta de Emenda à Lei Orgânica 001/2018, que foi aprovada em outubro de 2018 e terá vigência a partir de 2019.

O PL 005/2018 dispõe sobre a inclusão da disciplina de Língua Espanhola no currículo do ensino fundamental, anos finais, nas escolas municipais, com os seguintes encaminhamentos:

Art. $1^{\circ}$. A disciplina de Língua Espanhola será introduzida na rede municipal de ensino, além da língua Inglesa, no currículo do ensino fundamental/anos finais e na modalidade Educação de Jovens e Adultos (EJA).

Parágrafo único: a oferta da Língua Inglesa e Espanhola será opcional na regionalização para os anos iniciais e obrigatória do $6^{\circ}$ ao $9^{\circ}$ ano.

Art. $2^{\circ}$. As disciplinas serão ministradas por profissionais com formação em Letras - Licenciatura Plena, com habilitação específica em Língua Espanhola e ou Inglesa, conforme a disciplina. Parágrafo único: Em caso de contrato temporário será exigida do profissional contratado a mesma habilitação necessária para o cargo de professor de línguas. [...] (PL 005, 2018).

Já a Proposta de Emenda à Lei Orgânica 001/2018 acrescenta o parágrafo $\ 6^{\circ}$ ao artigo 134 da Lei Orgânica Municipal ${ }^{\text {iii: }}$

$\$ 6^{\circ}$ - O ensino de língua espanhola será introduzido na rede municipal de ensino, 


\title{
QUADRADO, Caroline Gonçalves Feijó; TROIAN, Alessandra
}

no currículo do ensino fundamental/anos finais (do $6^{\circ}$ ao $9^{\circ}$ ano) e na modalidade Educação de Jovens e Adultos (EJA).

Os dois documentos citados demonstram o compromisso político-educacional assumido pelo Legislativo em relação à oferta obrigatória de espanhol nos anos finais e a possibilidade de opção nos anos iniciais. Já que no âmbito federal continua-se caminhando em direção a uma política linguística "restrictiva y monolingüe” (FENÁNDEZ, 2018, p. 15). Entende-se que estas iniciativas locais podem significar um compromisso com uma política educacional e linguística plurilíngue, bem como com o "derecho de enseñar y aprender español en las escuelas fronterizas brasileñas" (ZWARG; ARF; BARREDA, 2018, p. 96).

As ações realizadas também demonstram certa consciência dos legisladores em relação ao ensino da língua considerando o cenário fronteiriço do município. Esta postura fica evidente na justificativa do PL 005/2018:

\begin{abstract}
Diante da legislação nacional determinar que apenas a língua inglesa será ofertada de forma obrigatória, e sendo nossa cidade fronteiriça ao Uruguai sabemos da importância do ensino da língua espanhola. O Brasil faz fronteira com 07 países de língua espanhola, o espanhol é a terceira língua mais falada no mundo, também é a língua oficial do MERCOSUL, todos esses são dados que nos demonstram a importância do tema (Projeto de Lei 005, 2018, s.p).
\end{abstract}

Apresentada a legislação proposta e a justificativa para sua criação, considera-se que também poderiam ter sido destacadas questões relacionadas à importância da formação do aluno enquanto sujeito fronteiriço, bem como a ideia de que, através da oferta do espanhol na educação básica, é possível ensinar os alunos sobre a importância da integração linguística, política, econômica, histórica e cultural entre os países vizinhos (BOÉSSIO, 2010). No entanto, reconhece-se que o município está dando os primeiros passos em direção a um fortalecimento do ensino do idioma em suas escolas.

Após a apresentação das políticas locais em relação ao ensino de espanhol, na próxima seção, será abordada a percepção do poder Executivo em relação aos limites e às perspectivas encontrados pela gestão educacional.

\subsection{Limites e perspectivas do ensino de espanhol em Jaguarão}

Após a reforma do ensino médio, buscou-se conhecer como está a oferta de espanhol nas escolas municipais de Jaguarão. De acordo com o Secretário de Educação (SE) e a Coordenadora Pedagógica (CP), as alterações realizadas, em 2017, na LDB, não resultaram alterações no currículo escolar, pois o ensino da língua continuou sendo ofertado. No entanto, os gestores relatam que, em 2018, a oferta da disciplina não ocorreu integralmente do sexto ao nono ano em todas as escolas municipais, devido à falta de professores. A falta de pessoal foi o principal limite encontrado para a 
oferta integral da disciplina. Em algumas escolas o conteúdo que seria ensinado em quatro anos, foi condensado para apenas dois.

\begin{abstract}
Nós temos um espanhol de sexto a sétimo ano, nos anos finais; de oitavo e nono de [...] inglês ou vice-versa, mas também tem escolas que têm o inglês como língua moderna e o espanhol, na integra, do sexto ao nono, devido à disponibilidade de professores. Como a gente não tem professores pra todos, fizemos esta disposição. (CP).
\end{abstract}

De acordo com os profissionais, mesmo com a condensação do ensino de espanhol, os alunos veem todo o conteúdo previsto e, embora os gestores tenham declarado que a alteração feita na LDB não resultou em mudanças no ensino de espanhol em Jaguarão, a ação de condensar em dois anos o currículo da disciplina em algumas escolas é um reflexo prático do esvaziamento do ensino do idioma no país.

A Lei 11.161/2005 constitui-se como uma política linguística de fortalecimento e ampliação do ensino de espanhol nas escolas brasileiras. Definia que a oferta do idioma era obrigatória pelos estabelecimentos de ensino, e a matrícula facultativa para o aluno. Também previa que a União estimularia e apoiaria os sistemas de ensino na execução dessa obrigatoriedade. Portanto, se esta lei estivesse vigente, existiria a possibilidade do município buscar outras alternativas para resolver o problema de pessoal, e não apenas a condensação do currículo.

Referindo-se especialmente a essa condensação vigente em Jaguarão, é possível compreender que a revogação da Lei 11.161/2005 pode ter dado condições para que o ensino de espanhol fosse colocado à margem no processo de formação dos alunos, limitando o contato formal dos discentes com outros idiomas durante a escolarização (FERNANDEZ, 2018). Embora o aluno esteja vendo toda a matéria proposta para os quatro anos das séries finais, a oportunidade de contato, de diálogo, de integração, de conhecimento e de valorização da língua do país vizinho, foi condensada em dois.

Entende-se o argumento dos gestores de que a situação está vigente apenas por falta de professores, no entanto, o que se quer mostrar é que ainda é necessário criar uma cultura nacional que reconheça a importância do ensino de língua espanhola nas escolas do Brasil. Dado o momento de transição, em que alguns estados e municípios estão legislando a respeito do ensino de línguas estrangeiras, considerando, refletindo e partindo de cada contexto, espera-se que essa cultura passe a ser fortalecida do âmbito local ao nacional.

Em Jaguarão, as perspectivas relacionadas ao futuro e a oferta integral do componente em todas as escolas está vinculada à realização, em 2019, de concurso e da nomeação de professores específicos para a área: 


\section{QUADRADO, Caroline Gonçalves Feijó; TROIAN, Alessandra}

[As mudanças ocorridas no ensino de espanhol foram resultado] do quadro de pessoal. Nós mantivemos o mesmo organograma que vinha. No ano que vem [2019], a ideia é, saindo o concurso, que é quase 100\% de certeza que vai sair, nós tendo interessados em fazer para espanhol, a gente vai completar com estes professores para poder oferecer espanhol de 6 a 9 em todas as escolas (SE).

No entanto, na fala do Secretário, não fica claro se serão propostas uma quantidade de vagas de professores de espanhol que dê conta de todas as escolas, ou se as vagas do concurso serão apenas para suprir as necessidades das escolas que não têm espanhol do sexto ao nono ano. De acordo com a Coordenadora Pedagógica, a ideia é buscar uma progressão no ensino de espanhol, construir, com a ajuda de professores de espanhol, um novo currículo, que transite entre as questões locais, de fronteira, mas que também prepare o aluno para agir e usar a língua no mundo.

São quatro anos de espanhol, a gente queria que esse espanhol fosse significativo pra ele, né. Junto com essa perspectiva de botar o professor nomeado em concurso para o espanhol somente, é que ele também ajudasse nesse currículo, que esse currículo fosse mais significativo (CP).

Apresentados os limites e perspectivas em relação ao ensino de espanhol em Jaguarão, a passagem a seguir pode evidenciar que, embora a legislação federal esteja deixando explícita a política monolíngue nacional, a partir da autonomia dos Estados e dos Municípios poderá ser implementada a cultura de valorização do ensino de outras línguas estrangerias partindo do âmbito local.

\footnotetext{
Eles dizem o que eu tenho que colocar. Bom, então eu tenho que colocar o inglês. Beleza, então eu coloco o inglês obrigatoriamente em todos. Mas eu posso colocar o espanhol. É uma prerrogativa minha... é... nossa, da secretaria, do município, nós vamos colocar (SE).
}

No caso de Jaguarão, conforme declarado pelo Secretário, a prerrogativa é ensinar o espanhol. No entanto, tem-se a liberdade de legislar a partir do que é importante para o contexto: "A gente sabe que em algumas regiões tu tem como segunda língua o alemão, então o que é interessante [é a escola ensinar o que é importante] pro meio" (SE).

As discussões realizadas nesta seção permitem identificar as ações que estão em tramitação nos poderes Legislativo e Executivo de Jaguarão, em busca do fortalecimento do ensino de espanhol nas escolas. Apesar da legislação federal não ter uma política linguística efetiva e contínua para o ensino de línguas estrangeiras, percebe-se que este cenário pode ser revertido a partir de ações locais, como é o caso de Jaguarão.

\section{Considerações finais}

A partir do cenário nacional que torna obrigatório apenas o ensino de inglês no ensino fundamental, o Legislativo de Jaguarão propôs o Projeto de Lei 005/2018 e realizou a alteração de sua Lei Orgânica 001/2018 para obrigatoriedade do ensino de espanhol no município, a partir de 
2019. A ação demonstra o compromisso político-educacional assumido pela gestão educacional em relação à oferta obrigatória de espanhol nas séries finais, na EJA, a possibilidade de opção nos anos iniciais, além da obrigatoriedade das disciplinas serem ministradas por profissionais com formação em Letras e habilitação específica em espanhol.

No entanto, o ensino de espanhol no município sofreu uma condensação devido à falta de professores para ministrar a disciplina. Em 2018, das oito escolas municipais, quatro ofertaram o componente integralmente do sexto ao nono ano do ensino fundamental e outras quatro apenas no sexto e sétimo ano. Embora os gestores educacionais não relacionem a condensação à alteração da $\mathrm{LDB}$, acredita-se que, se ainda fosse obrigatória a oferta do espanhol no ensino fundamental, teriam de ter sido buscadas outras alternativas para a manutenção da oferta integral do idioma.

Como limite para o fortalecimento do ensino do idioma no município foi evidenciada a falta de pessoal. O município não tem um quantitativo suficiente de professores que possibilite a oferta do idioma do sexto ao nono ano em todas as escolas. Assim, entende-se que as iniciativas locais podem demonstrar um compromisso com o direito de ensinar e aprender uma língua estrangeira, especialmente aquela que é necessária ao contexto. Pesquisa realizada e apresentada pela primeira autora para a obtenção do título de especialista em Gestão Pública Municipal pela Unipampa

\author{
Notas explicativas \\ ${ }^{1}$ Pesquisa realizada e apresentada pela primeira autora para a obtenção do título de especialista em Gestão \\ Pública Municipal pela Unipampa \\ ${ }^{2}$ Michel Temer
}

\title{
Referências
}

ALVAREZ, M. L. O. A des(valorização) do ensino do Espanhol no Brasil. In: MIRANDA, Cícero. La lengua española en Brasil: Enseñanza, formación de professores y resistencia. Brasília: Consejeria de Educación da Embaixada, 2018, p 19-27.

BARDIN, L. Análise de conteúdo. São Paulo: 70ª ed, 2011.

BOESSIO, C. P. D. Práticas docentes com o ensino da língua espanhola nas séries iniciais. 2010. Disponível em: < http://livros01.livrosgratis.com.br/cp147192.pdf>. Acesso em: 11 out. 2018.

BRASIL. Lei de Diretrizes e Bases da Educação Nacional (LDB): lei n. 9.394, de 20 de dezembro de 1996. LDB/96. Estabelece as diretriz̧es e bases da educação nacional. Brasília: Ministério de Educação e Cultura.

BRASIL. Ministério da Educação. Secretaria da Educação Básica. Base nacional comum curricular. Brasília, 2016.2 Disponível em: <http://basenacionalcomum.mec.gov.br/\#/site/inicio>. Acesso em: out. 2018. 
BRASIL. Orientações Curriculares para o Ensino Médio (OCEM). Conhecimentos de Espanhol Secretaria de Educação Básica. Brasília: Ministério de Educação, 2006.

BRASIL. Parâmetros Curriculares Nacionais - Ensino Médio (PCN). Linguagens, Códigos e suas Tecnologias. Conhecimento de Língua Estrangeira Moderna. Secretaria de Educação Básica. Brasília: MEC, 2000.

CARVALHO, F. P. Representações sobre ensino de espanbol como lingua estrangeira: entre a possibilidade e a contingência. Disponível em: <http://www.seer.ufu.br/index.php/letraseletras/article/view/33288/19147>. Acesso em: 10 out. 2018.

CERVO, A. L.; BERVIAN, P. A.; DA SILVA, P. Metodologia cientifica. 6 ed. São Paulo: Pearson Prentice Hall, 2007.

Documento Marco Multilateral Referencial de Desarrollo Curricular (DMMRDC). Disponível em: $<$ http://edu.mercosur.int/pt-BR/tratados/finish/54-escolas-de-fronteira-escuelas-defrontera/9-marco-multilateral-referencial-dedesenvolvimento-curricular.html $>$. Acesso em: 01 de set 2018.

FARIAS-MARQUES, M. do S. de A. Um olhar para o ingresso especifico para uruguaios fronteiriços na UNIPAMPA - câmpus Jaguarão: Por uma política linguística e educacional integracionista no entremeio identitário. 2016. Disponível em: < http://pos.ucpel.edu.br/ppgl/wpcontent/uploads/sites/4/2018/03/Um-Olhar-Para-o-Ingresso-Específico-Para-UruguaiosFronteiriços-na-UNIPAMPA-Maria-do-Socorro-de-Al.pdf $>$. Acesso em: 12 out. 2018. FERNÁNDEZ, G. E. Políticas públicas para la (no) enseñanza de español en Brasil. In: MIRANDA, Cícero. La lengua española en Brasil: Enseñanza, formación de professores y resistencia. Brasília: Consejeria de Educación da Embaixada, 2018.

GUI, R. T. Grupo focal em pesquisa qualitativa aplicada: intersubjetividade e construção de sentido. 2003. Rev. Psicol., Organ. Trab, Florianópolis, v.3 n.1, p.1-16, jun. 2003.

MARCONI, M. A.; LAKATOS, E. M. Fundamentos de metodologia cientifica. 7 ed. São Paulo: Atlas, 2010.

SILVEIRA, D. T.; CÓRDOBA, F. P. A pesquisa científica. In: GERHARDT, Tatiana Engel; SILVEIRA, Denise Tolfo. Métodos de pesquisa. Porto Alegre: Editora da UFRGS, 2009.

SOUZA, C. POLÍTICAS PÚBLICAS: questões temáticas e de pesquisa. Caderno Crh, Salvador, n. 39, p. 11-24, jul./dez. 2003

STURZA, E. R. La enseñanza de la lengua española en el contexto de frontera: realidades y desafíos. In: MIRANDA, Cícero. La lengua española en Brasil: Enseñanza, formación de professores y resistencia. Brasília: Consejeria de Educación da Embaixada, 2018.

ZWARG, J. D.; ARF, L. M. G.; BARREDA, S. V. M. Formación de profesores de español en Corumbá $(M S)$ : perspectivas fronterizas y desafíos. In: MIRANDA, Cícero. La lengua española en Brasil: Enseñanza, formación de professores y resistencia. Brasília: Consejeria de Educación 
da Embaixada, 2018, p 19-27.

Recebido em: 01 fev. 2019 / Aprovado em: 31 out. 2019

\section{Para referenciar este texto}

FEIJÓ-QUADRADO, Caroline Gonçalves; TROIAN, Alessandra. O ensino de espanhol na fronteira de Jaguarão/BR e Rio Branco/UY: análise dos limites e perspectivas educacionais após revogação da Lei nº 11.161/2005. Cadernos de Pós-graduação, São Paulo, v. 18, n. 2, p. 15-28, jul./dez.

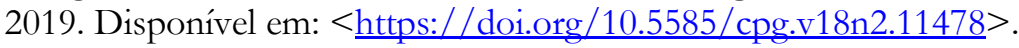

